\section{Questões atuais sobre a vigilância sanitária das concentrações de flúor em alimentos}

\author{
Current issues regarding health surveillance \\ of fluoride concentrations in foods
}

\begin{abstract}
This study analyzed the position of the Federal (Brazil), State (São Paulo), and municipal (Bauru, São Paulo) governments, civil society representatives, the regulated sector, and research associations concerning issues with fluoride content in foods. Analysis of the interviews $(N=15)$ used a qualitative methodology (collective subject discourse theory). Various central ideas were identified, including the need for stronger health surveillance in monitoring and controlling fluoride levels, educational measures, and more research in the area. The study concludes that the health surveillance approach to fluoride levels in foods is necessary, but still incipient. There is a mismatch between research output and surveillance. Regulation alone does not suffice to solve all the issues. Health risk communication and health education measures need to be implemented. Issues with fluoride on food labels need further research for the intervention to be effective.
\end{abstract}

Dental Fluorosis; Fluorine; Food; Qualitative Research; Health Surveillance
Priscila Ariede Petinuci Bardal 1 Kelly Polido Kaneshiro Olympio 2 Marília Afonso Rabelo Buzalaf 2 Sueli Gandolfi Dallari 1

\section{Introdução}

A globalização, a crescente industrialização e o surgimento de novas tecnologias são características marcantes na sociedade atual. Neste sentido, o risco sanitário se apresenta, muitas vezes, de forma silenciosa.

No que diz respeito à fluorose dentária, este risco é verificado pela ingestão excessiva de flúor durante o período de formação dos dentes através de várias fontes: dentifrícios, suplementos, água fluoretada, fórmulas infantis e alguns alimentos e bebidas infantis industrializados 1,2,3.

"O século XX foi marcado, no âmbito da saúde bucal coletiva, pela descoberta das possibilidades preventivas do flúor... A luta dos dentistas sanitaristas contra a mutilação dentária teve no flúor um aliado fundamental, mas a continuidade do seu uso em ações de saúde pública requer medidas de vigilância sanitária cada vez mais precisas, sem as quais há risco de produção iatrogênica de fluorose dentária em níveis inaceitáveis" 4 (p. 390).

A vigilância sanitária como campo regulatório da sociedade moderna destina-se ao controle dos riscos sanitários 5 . Sua atuação se torna cada vez mais complexa, principalmente quando se verifica a compartimentalização da produção. No caso brasileiro, existe um grande desafio na construção de um campo de conhecimento em vigilância sanitária em consonância com o Sistema Único de Saúde (SUS), em decorrência 
da complexidade de saberes envolvidos em sua atuação como uma política de proteção ${ }^{6}$. Neste sentido, é crucial que a Agência Nacional de Vigilância Sanitária (ANVISA) esteja submetida a mecanismos eficazes de prestação de contas e controle democrático 7 .

A Constituição Federal em seu art. 196 declara que um dos deveres do Estado para a garantia do direito à saúde é a redução dos riscos de doenças e outros agravos à saúde. Trata-se de uma tarefa complexa, já que a própria noção do risco sanitário depende de uma série de variáveis: econômicas, culturais, sociais, morais e políticas. Há uma fragmentação na organização dos serviços de vigilância que, muitas vezes, provocam duplicidade de ações ou, pior ainda, vácuos de vigilância 8 .

Desta forma, o presente estudo pretendeu conhecer e analisar os posicionamentos do poder público federal (Brasil), estadual (São Paulo), municipal (Bauru, São Paulo), de representantes da sociedade, do setor regulado e de associações brasileiras ligadas à pesquisa científica, sobre a vigilância da concentração de flúor em produtos alimentícios, buscando, assim, gerar conhecimento para subsidiar ações de vigilância sanitária sobre esta temática.

\section{Métodos}

Foram coletados 15 depoimentos de representantes de instituições que, direta ou indiretamente, estão envolvidas com as questões referentes à vigilância sanitária das concentrações de flúor em produtos alimentícios:

- Nível municipal: Secretaria Municipal de Saúde; Direção Geral da Vigilância Sanitária; Coordenação de Odontologia na Vigilância Sanitária e Coordenação de Nutrição na Vigilância Sanitária.

- Nível estadual: Direção de Alimentos do Centro de Vigilância Sanitária (CVS) da Secretaria de Saúde do Estado de São Paulo e Direção Técnica da Divisão de Produtos Relacionados à Saúde do CVS.

- Nível federal: Coordenação Nacional de Saúde Bucal do Ministério da Saúde e Gerência Geral de Alimentos e Produtos especiais da Agência Nacional de Vigilância Sanitária.

- Representantes da sociedade: Conselho Municipal de Saúde do Município de Bauru e Instituto Brasileiro de Defesa do Consumidor.

- Setor regulado: Associação Brasileira das Indústrias da Alimentação e Associação Brasileira da Indústria de Águas Minerais.

- Associações brasileiras ligadas à pesquisa científica: Associação Brasileira de Pós-gradua- ção em Saúde Coletiva; Associação Brasileira de Odontologia e Associação Paulista dos Cirurgiões-dentistas.

Os entrevistados responderam a oito questões: (1) "Qual o posicionamento do(a) <Instituição> sobre a vigilância da concentração de flúor em alimentos industrializados, incluindo bebidas e águas minerais?”; (2) “ $O(A)<$ Instituição>, direta ou indiretamente, tem tido acesso às pesquisas sobre flúor em alimentos industrializados, bebidas e águas minerais, especialmente aqueles mais consumidos por crianças em idade de risco à fluorose dentária?”; (3) "O(A) <Instituição> tem se envolvido na implementação de alguma política pública sobre vigilância da concentração de flúor em alimentos industrializados, bebidas e águas minerais? Se sim, de que forma?"; (4) "Quais perspectivas futuras a respeito desse assunto?”; (5) "O(A) <Instituição> teria alguma sugestão ou estratégia para a realização dessa vigilância do flúor, tendo em vista a prevenção da fluorose dentária? Se sim, quais seriam?"; (6) “Como o(a) <Instituição> se posiciona a respeito da necessidade de informações nos rótulos sobre a concentração de flúor presente em alimentos industrializados, bebidas e águas minerais?"; (7) “Seria viável?" e; (8) “Como seria feita a orientação da população para que compreenda essas informações disponibilizadas?".

As respostas foram analisadas com o auxílio do QualiQuantiSoft (Lefèvre F \& Lefèvre AMC, Faculdade de Saúde Pública, Universidade de São Paulo/Sales \& Paschoal Informática, São Paulo, Brasil) um software de apoio para análise de estudos qualiquantitativos, baseado na teoria Discurso do Sujeito Coletivo (DSC), uma proposta metodológica para pesquisas sociais que busca descrever e interpretar as representações sociais 9 .

Ao analisar o material verbal coletado, extraem-se dele as ideias centrais e suas correspondentes expressões-chave. Com as expressõeschave de sentidos semelhantes, compõem-se os discursos síntese na primeira pessoa do singular 10 . Isto produz no leitor um efeito da "coletividade falando" e apresenta uma densidade semântica nas representações sociais 11,12.

A coleta de dados foi realizada após a obtenção do parecer favorável do Comitê de Ética em Pesquisa da Faculdade de Saúde Pública, Universidade de São Paulo (Of. COEP/058, protocolo 1620).

\section{Resultados e discussão}

Uma marcante característica da promoção da saúde é que ela agrega diferentes disciplinas e di- 
versos setores, o que permite um melhor dimensionamento sobre a complexidade das ações, dos processos e dos impactos 13. É possível então, abordar a saúde em seu conceito amplo, discutindo a busca da qualidade de vida, com o pressuposto de que, para a solução dos problemas, exige-se o estabelecimento de alianças e a mobilização da sociedade, sempre levando em conta o respeito ao planejamento e poder local 14 .

Lucchesi 5 afirma que apenas um adequado sistema de pesos e contrapesos, bem como conjunto ativo de mecanismos de controle e participação social é capaz de tornar o sistema de vigilância sanitária eficiente do ponto de vista do equilíbrio entre os atores sociais envolvidos nos sistemas, sejam eles atores públicos ou privados.

No presente estudo, ao dar voz aos diversos atores sociais, observou-se que muitas falas pontuaram que a atuação da vigilância sanitária sobre as concentrações de flúor em produtos alimentícios é extremamente importante. No entanto, parece ainda, incipiente. Há necessidade de implementação das ações sobre monitoramento, controle e heterocontrole das concentrações de flúor.

DSC: “...Acho que teria que ter monitoramento. É necessário criar mecanismos de controle e de heterocontrole. É importante também que a sociedade não só monitore, mas participe da construção desta política de vigilância... não existe uma fiscalização da vigilância efetiva sobre esses produtos...".

O poder público deve garantir o desenvolvimento de um sistema de heterocontrole da dosagem de flúor nas águas de consumo, desenvolvimento de tecnologias mais precisas e de fácil operação para análise e controle dos teores de flúor em diversas fontes, monitoramento da prevalência de fluorose através de um sistema de informação consistente, além de ações de educação para a população 15,16 . Ademais, a vigilância e as atividades de pesquisa devem ser realizadas a fim de se avaliar o efeito da exposição total de flúor 17 .

Segundo Paracelsus (1493-1541): “Tudo é tóxico. A dose certa diferencia o veneno do remédio" 18 (p. 177). Esta frase adequa-se ao caso do flúor. Felizmente, não há muito registros sobre toxicidade aguda provocada por produtos dentais na odontologia 18. Em sua grande maioria, as pesquisas sobre toxicidade do flúor se referem às questões crônicas, como a fluorose dentária.

O uso do flúor tem contribuído de forma expressiva para a redução das desigualdades em saúde. No entanto, promover saúde significa também garantir o direito do cidadão ao acesso às medidas coletivas seguras, às políticas públicas que garantam a saúde, à autonomia das es- colhas, ao acesso à informação e à participação nas decisões que influenciam sua vida e saúde. Portanto, é importante salientar a importância das estratégias sobre o controle de fatores de risco e o incremento de fatores de proteção contra a fluorose dentária 19.

Neste sentido, os depoimentos dos participantes da pesquisa apresentaram a necessidade de um maior esclarecimento e ações de educação em saúde junto aos consumidores e produtores sobre as questões da vigilância do flúor em alimentos e bebidas.

DSC: “...Hoje a vigilância sanitária já tem um foco educativo... se você exigir que uma pessoa faça alguma coisa, ela tem que entender o porquê que ela está fazendo aquilo... se é realmente um problema a concentração de flúor nos alimentos e nas bebidas, eu acho que a gente tem que trabalhar essa população consumidora e a população produtora. É um trabalho bem abrangente...".

Nas entrevistas realizadas destacou-se também que a regulamentação sobre as concentrações de flúor nos alimentos e bebidas é necessária, mas não suficiente por si só, para abordar todos os aspectos referentes à ingestão de flúor. Citou-se a importância do estabelecimento de limites para as concentrações de flúor nos produtos alimentícios. No entanto, enquanto alguns entrevistados não sabiam se havia alguma regulamentação a respeito, outros já destacavam a existência de normas brasileiras sobre flúor, que citam a ingestão diária recomendada (IDR), bem como a questão de informações nos rótulos das águas minerais.

DSC: “...A regulamentação é vista com bons olhos... mas a política se constrói no dia a dia, é uma frente de alta complexidade, porque ela está tratando fundamentalmente de promoção da saúde... estamos falando de políticas intersetoriais. Não é uma política que se resolve com a publicação de uma portaria só. Ela vai se institucionalizar na medida em que ela vai se colocando...".

O art. 198 da Constituição Federal vigente destaca a competência das três esferas de poder público da federação: União, estados e municípios. Também prevê que a obrigação de editar normas de "proteção e defesa da saúde" é competência concorrente dessas mesmas esferas. Na verdade, "cuidar da saúde" é tarefa de todos. Sendo assim, cabe à União produzir e aprovar normas gerais, que devem ser suplementadas pelos estados, as quais, por sua vez, serão complementadas por normas elaboradas e aprovadas pelos municípios 20 .

No que diz respeito às regulamentações na área de vigilância sanitária de alimentos, os estados e municípios são competentes para suplementar a legislação sanitária aprovada pela 
União, cabendo aos municípios aprovar e aplicar regulamentações sobre assuntos de interesse local, no sentido de preservar a saúde de seus munícipes. A legislação sanitária vigente serve de parâmetro para traçar limites de controle 21 .

A ineficiência das ações de vigilância sobre o tema foi verificada nas entrevistas.

DSC: “...Que a gente possa cobrar dos nossos governantes para que tenha mais de atenção quanto a isso. Eu acho que não existe uma efetiva vigilância sobre a concentração de flúor nesses produtos. O flúor não aparece na Política Nacional de Alimentação e Nutrição e não faz parte dos programas nacional e nem estadual de análise de produtos industrializados...".

Para tentar compreender esses achados, Ely et al. 22 afirmam que as práticas de vigilância da saúde somente serão efetivas com a integração da equipe de saúde com a sociedade e outros setores governamentais. Destaca-se a importância do agir intersetorial na resolução dos problemas coletivos de saúde.

Ademais, há necessidade de investimentos tanto na formação dos pesquisadores que deverão dominar também as ciências sociais - na teoria e na prática - para serem capazes de comunicar à sociedade os resultados de seus experimentos, quanto na formação das pessoas em geral, que necessitam conhecer as bases do conhecimento científico para escolherem qual o grau de risco a que consideram aceitável submeterem-se 23 .

Vários entrevistados pontuaram a necessidade de formação de redes efetivas para a realização da vigilância sanitária das concentrações de flúor nos produtos alimentícios.

DSC: "Tem que ser montada uma rede pra tudo isso, porque os municípios não têm laboratórios, por exemplo... teria que formar toda uma rede que participasse diretamente, com o município coletando amostras, participando da discussão, apontando os resultados, educando as pessoas nesse sentido. Acho que deveríamos construir em conjunto com o poder público uma estratégia que possa ser eficiente...".

Neste sentido, de acordo com Ely et al. 22, a saúde é um bem construído socialmente e envolve múltiplos fatores determinantes, tornando-se então imprescindível a busca por parcerias em outros setores governamentais e não-governamentais, transcendendo os espaços convencionais da área da saúde, de forma a contribuir na construção de políticas públicas saudáveis.

O momento atual impõe à prática odontológica a necessidade de se pensar globalmente, mesmo frente a problemas locais. A verdade é que problemas complexos exigem respostas complexas. O maior acesso à informação e ao co- nhecimento, num diálogo franco que estimula o protagonismo coletivo, pode auxiliar a construção de práticas multidisciplinares e intersetoriais que respondam adequadamente às necessidades das sociedades contemporâneas 14 .

A implementação de programas e ações já existentes através da inserção das questões do flúor é uma alternativa a se considerar, conforme explicitado nos depoimentos dos entrevistados. No nível estadual, foram citados, como exemplos, o Programa de Vigilância da Qualidade da Água para Consumo Humano (Proágua) e o Programa Paulista de Análise Fiscal de Alimentos. No nível federal, falou-se sobre o Centro Colaborador em Vigilância em Saúde Bucal (CECOL) que faz parte da Política Nacional de Saúde Bucal do Ministério da Saúde, além da Política Nacional de Alimentação e Nutrição.

Verificou-se também que há um descompasso entre a produção científica e as ações da vigilância sanitária. Discussões mais aprofundadas sobre o tema ainda continuam restritas ao meio acadêmico, em especial, à classe odontológica. As universidades têm que gerar conhecimentos de modo que sejam aplicados. No entanto, conforme observado nos discursos, o acesso às pesquisas sobre flúor em alimentos industrializados, bebidas e águas minerais ainda é incipiente.

DSC: “...eu não tenho tido acesso a esse tipo de pesquisa. Se é que ela existe, ela não chega na ponta... Eu acho, na verdade, que a gente tem um certo descompasso ou desarticulação entre a pesquisa e o que a gente efetivamente está fazendo...”.

Isto é deveras preocupante, pois, embora se saiba que os processos legislativos e normativos são complexos, sabe-se também que tem maior chance de não chegar a resultados adequados se estiverem embasados em conhecimentos científicos precários 24. Para processos de decisão em saúde, tal como a formulação de políticas, necessita-se de conhecimentos relacionados às condições de saúde, aos seus determinantes, à efetividade das ações propostas, entre outros 25 .

Pode-se então, através do que foi verificado nos depoimentos, considerar a necessidade da criação de mecanismos para que universidades e vigilância sanitária caminhem juntas. Que um espaço de discussão entre estas seja efetivado de modo a contribuir para as questões de definição de prioridades de atuação e de pesquisa, estabelecimento de regulações sanitárias e ações de monitoramento e controle, incluindo-se nestas, as questões relativas ao flúor.

Os depoimentos citaram também a necessidade de desenvolvimento de mais pesquisas sobre as fontes de ingestão de flúor e a realização de estudos longitudinais sobre a prevalência de flu- 
orose dentária, com o envolvimento de equipes multidisciplinares, para uma abordagem mais ampla do tema.

DSC: "Eu acho que há muita coisa pra ser feita e requer também muitas pesquisas. Penso que é preciso que a academia, os pesquisadores, forneçam elementos científicos suficientes para que se confirme primeiro, como risco de saúde pública e depois, analisar esse risco do ponto de vista da sua magnitude e da sua abrangência, pra que isso seja objeto de normatização. É preciso acompanhar o mundo científico, novas pesquisas científicas e elaboradas, com trabalho publicado...".

Nas sociedades modernas, o exercício do poder de formulação de políticas está centrado no Estado, que necessita de conhecimentos técnicocientíficos atualizados para o exercício a contento desta tarefa. No contexto brasileiro, seguindo essa tendência, o processo de consolidação do SUS e a consequente ampliação do setor público, nas funções de suprir as necessidades de saúde da população e de regular os fatores relacionados com a saúde, têm levado os organismos encarregados desta tarefa, a ampliar suas demandas por conhecimento científico. A realização da I Conferência Nacional de Ciência e Tecnologia em Saúde, em 1994, foi o marco nesse processo, por aprofundar o debate sobre ciência e tecnologia no interior das discussões sobre o SUS 24,25.

De acordo com Coimbra Jr. ${ }^{26}$, mesmo com certos limites dos financiamentos, a comunidade científica brasileira em saúde tem ampliado sua produtividade. O aumento da sua capacidade de responder às necessidades dos processos de elaboração de políticas em saúde será uma consequência do fortalecimento dos laços entre os órgãos decisórios, legislativos, normativos e regulatórios e os centros de investigação científica e desenvolvimento tecnológico, que contribuirá para estabelecer um novo patamar na relação entre a comunidade científica e as funções constitucionais, legais e morais do estado, no campo de saúde.

A maioria dos problemas de saúde, inclusive aqueles referentes aos riscos, caracteriza-se por um estado fluido e incompleto de conhecimento científico 27. A organização do Estado brasileiro, no que se refere à vigilância dos riscos de doenças e outros agravos à saúde, é fragmentada, havendo a vigilância sanitária (bens, produtos e serviços), a vigilância epidemiológica (doenças transmissíveis e investigações de outros riscos) e a vigilância ambiental em saúde (meio ambiente em geral, inclusive o do trabalho). Esta fragmentação provoca problemas de gestão e de consolidação de informações na defesa da saúde. Devese pensar na organização das vigilâncias dentro de um sistema único e coordenado, denominado
Sistema Nacional de Vigilância em Saúde, que articule as diferentes especialidades de vigilância em saúde hoje existentes no Brasil e possibilite um sistema de informações e ações de vigilância de forma eficaz e resolutiva 8 .

Algumas das medidas para se evitar os efeitos indesejáveis da toxicidade crônica do fluoreto podem ser de aspecto político. Neste sentido, a classe odontológica deve estar mobilizada e informada sobre os reais benefícios do fluoreto. Pode-se ter uma posição racional sobre o uso do flúor sem posturas deveras radicais que consideram o fluoreto um "mal necessário" ou simplesmente um "veneno" a ser evitado a todo custo 28 . Estas afirmações vão também ao encontro das falas dos entrevistados.

DSC: “...Sou favorável ao uso racional do flúor... tem que ser usado com critério e indicação terapêutica. Preventivo sim, na água de abastecimento, isso não se discute, desde que haja um controle da quantidade correta de flúor. Acho que o melhor antídoto é socializar as informações. Quanto mais informação fique na mão de poucas pessoas, pior pra todo mundo. É uma questão que nós temos que levar pra sociedade, pra desmistificar o uso racional do flúor. A gente precisa ter também um posicionamento firme porque existem envolvimentos empresariais, por exemplo, que podem levar ao uso indiscriminado do flúor...".

Torna-se imperativa a apropriação da concepção de território, a inclusão de novos atores sociais e a análise das situações de saúde, dos ambientes de trabalho, da educação e comunicação em saúde e dos riscos ambientais como estratégias de intervenção nas questões locais, para que se promova a efetividade das ações em odontologia 22. Na construção do SUS, as ações desenvolvidas não devem limitar-se às melhorias dos padrões técnicos ou às condutas definidas em gabinetes.

Sobre as questões de rotulagens do elemento flúor, abordadas nas entrevistas, acredita-se que estas precisam de um maior amadurecimento. Pela análise dos depoimentos, a informação sobre flúor nos rótulos não será, isoladamente, uma medida efetiva de proteção. Além das várias informações presentes nos rótulos, as letras utilizadas são de difícil visualização e o entendimento é dificultado pelo uso de termos técnicos. Para ser considerada realmente uma medida assertiva, o consumidor precisará, além de ler aquilo que está no rótulo, entender e aplicar tais informações.

DSC: “...eu acho que é uma questão de educação sanitária. Não adianta exigir em rótulo, que exista a informação, se o consumidor não criar o hábito de leitura desse rótulo e de ter capacidade de absorver daquela informação qual é o risco a 
prevenir... Existe uma grande quantidade de normas estabelecendo o que pode ou não escrever no rótulo, sem antes pesquisar o interesse do consumidor pelas informações, qual é a percepção pública de rótulo, qual é o senso comum da informação sobre rótulo. Ficam normatizando sem saber se aquilo funciona ou não...”.

Observou-se também que é preciso considerar que alterações na legislação precisam ser harmonizadas no MERCOSUL (Mercado Comum do Sul). Desta forma, para se propor modificações da rotulagem, é necessária uma justificativa científica consistente. Neste sentido, depoimentos sugeriram que o caminho para esta questão de vigilância poderia ser, por exemplo, um controle interno das indústrias, com limites pré-estabelecidos em relação ao flúor, a se seguir, sem necessariamente ter que incluir as informações nos rótulos.

DSC: “...Uma rotulagem muito extensa, a gente tem que pensar na compreensão do consumidor. E para o flúor, pra que a gente possa chegar ao MERCOSUL, precisaria ter dados que comprovassem realmente o seu risco hoje nos produtos. Será que não seria mais importante a gente estabelecer determinados limites que não precisariam aparecer nos rótulos, mas que as indústrias precisariam seguir e que a gente estaria dando uma proteção de qualquer forma?".

O estudo realizado por Teixeira et al. 29 verificou que $59 \%$ da população entrevistada lêem as informações nutricionais do rótulo. Observouse modificação na compra e no consumo do alimento, principalmente com base na informação do valor calórico. Quanto ao entendimento do conceito de valores diários, percebe-se que a informação não é bem compreendida pelos consumidores. Segundo os autores, é importante uma ação educativa para a massificação da leitura e entendimento de tais informações.

Quando se abordam informações sobre concentrações de flúor, há de se ter também o cuidado para que a informação disponibilizada não provoque um comportamento diferente daquele para o qual ela foi desenvolvida e divulgada. Por isso, a importância do esclarecimento da população em geral e dos profissionais de saúde sobre o uso racional do flúor, seus benefícios e seus potenciais riscos. Neste sentido, os depoimentos apontam o importante papel da mídia.

DSC: “...pra você trabalhar rotulagem nutricional com população não é fácil. Hoje, na minha opinião, a forma mais eficiente seriam campanhas educativas nos meios de comunicação... todas essas campanhas são caríssimas, mas seria o ideal. Porque quando a gente coloca no site essas informações, o acesso a site ainda é muito pequeno e, a população que talvez mais necessitasse, não tem acesso. Hoje também eu estou meio descrente de folhetos...".

A alimentação é influenciada pelo que a mídia indica. O rápido avanço do conhecimento na área de alimentos bem como de ingredientes funcionais, em geral, confunde a população sujeita à transmissão de informações desvinculadas de significado 30 .

Segundo Sampaio 18, é importante que se reconheça o elemento flúor dentro de uma perspectiva imparcial e que ele seja visto com todas as suas vantagens, bem como as suas desvantagens e limitações quando do seu uso.

Os entrevistados pontuaram também tópicos relativos à fiscalização e ao monitoramento para que aquilo que for declarado no rótulo seja, de fato, o que se encontra nas análises.

Nesta perspectiva, é inegável a contribuição do conjunto de normas e leis à rotulagem no Brasil. No entanto, é necessário transformar a intenção em ação. A aplicação da legislação precisa ser alvo de efetiva fiscalização 31 .

DSC: “...Acho que o flúor sem dúvida deve ser informado, mas simplesmente informar a quantidade de flúor nos rótulos não é suficiente. Uma coisa é você botar no rótulo e outra coisa é realmente ter. Acho que nós temos muita coisa para se avançar ainda com relação à certificação de alimentos...".

Em pesquisa sobre rotulagens de alimentos industrializados no Brasil, verificou-se que a fiscalização ineficiente foi destacada como principal fator para o descumprimento das normas estabelecidas para a rotulagem de alimentos no Brasil 31.

De acordo com Coutinho $32,43 \%$ dos consumidores brasileiros, no ato da compra dos alimentos, buscam informações sobre os benefícios para a saúde nas embalagens dos produtos. Martins 33 concluiu que $61 \%$ dos entrevistados frequentadores de supermercados liam os rótulos dos produtos que compravam; porém, tal conduta referia-se, particularmente, àqueles consumidores com problemas de saúde ou de classe social mais elevada. Por outro lado, vários estudos identificaram a dificuldade do consumidor de compreender as informações disponibilizadas nos rótulos dos alimentos por não serem claras. Além disso, muitos consumidores não conheciam a rotulagem nutricional, e alguns nem demonstraram interesse por esses dados 33,34 .

DSC: “...sou a favor que se melhore a qualidade da informação ou que se especifique de forma mais chamativa o que se pretende coibir de risco, porque para o que hoje se exige, a letra é minúscula, há dificuldade de leitura, dificuldade de entendimento dos termos que estão ali....”. 
A leitura dos rótulos dos alimentos não implica, necessariamente, intenção de compra por parte do consumidor 34 . Apenas $23,6 \%$ dos entrevistados modificaram os seus hábitos alimentares em decorrência das informações presentes nos rótulos, enquanto a maioria $(62,2 \%)$ afirmou desconhecer a rotulagem nutricional. Torna-se necessário implementar ações educativas que esclareçam aos indivíduos a importância de considerar as informações nutricionais.

A educação ocorre formal ou informalmente na vida social. Ela se beneficia da instrução, mas a instrução não significa necessariamente educação. A educação é experimentada de maneira distinta pelos indivíduos e populações, reflete valores sociais, históricos, contextos socioculturais e políticos, ideologias, condições de vida e práticas pedagógicas 35 .

É através da educação que as pessoas são preparadas. É um processo de construção do conhecimento, de desenvolvimento da consciência crítica e capacidade de intervenção, tendo em vista a transformação da realidade. No entanto, precisa atingir igualmente a população, suas lideranças, gestores públicos, políticos, legisladores e os movimentos sociais organizados 36 . A respeito disto, os entrevistados destacaram a necessidade de implementação das práticas de educação em saúde.

DSC: “...A vigilância sanitária trabalha com a construção de uma ação educativa, mas o ideal seria chegar mais perto da população. Acho que está na hora de definir quais são as eficientes estratégias que a vigilância sanitária, capilarizada nos 5.800 municípios do Brasil, pode atuar dentro da área da saúde, junto com os programas de atenção básica, saúde da família, na articulação com o Conselho Municipal de Saúde, com entidades de consumidores, entre outros, na compreensão desta temática. Eu falo sempre que saúde não se faz sem educação. Não se pode fazer um alarmismo em cima do flúor, mas deve ter orientação. Este tema merece ser abordado pelas autoridades, pelo meio acadêmico e pela defesa do consumidor...”.

Durante as análises dos discursos dos entrevistados, foi possível observar que a vigilância sanitária muitas vezes não tem a "voz" que gostaria de ter nos meios de comunicação. Percebeu-se ainda que os aspectos da comunicação do risco sanitário, educação e orientação da população em relação ao tema precisam ser implementados para a real promoção da saúde. Adicionalmente, há necessidade de maior capacitação dos trabalhadores da vigilância sanitária e profissionais de saúde, neste sentido.

DSC: “...A midia é a grande formadora e a gente tem pouco tempo nos canais de televisão, rádios, jornais. Eu acho que está na hora da gente fazer um trabalho em cima disso. Porque a gente percebe aí a fluorose... só quando existe um grande problema é que a gente acaba tendo a "voz" que gostaria de ter todo dia... Um espaço que a sociedade merece ter para conhecer o que consumir e com qual segurança consumir determinados produtos...".

Costa \& Rozenfeld 37 afirmam que, uma vez identificados os riscos, é preciso empreender ações de controle. Para isto, além da legislação e da fiscalização, devem ser utilizados certos instrumentos, entre eles, a comunicação e a educação sanitária e os sistemas de informação.

De acordo com Vecina Neto et al. ${ }^{38}$, a vigilância sanitária é um campo de práticas construído por diversas áreas do conhecimento. $\mathrm{O}$ grande desafio é o de articular essas áreas para atender a sua função de proteção e promoção da saúde e de gestão do risco sanitário. As dimensões tecnológicas, políticas, sociais, culturais, econômicas, entre outras, são inerentes a todos os espaços de atuação da vigilância sanitária, levando à necessidade de profissionais capacitados e articulados com outros espaços de especialidades. A ação da vigilância sanitária deve ser balizada pela regra (lei, portaria, resolução ou outra hierarquia legislativa) e esta deve ser fruto do conhecimento, o qual deve ser produzido a partir de um espaço cooperativo entre a vigilância sanitária e a sociedade, cooperação esta que ainda se encontra em construção. Nos órgãos de vigilância sanitária não é possível encontrar todo o conhecimento necessário no enfrentamento de realidades cada vez mais complexas e de riscos sanitários oriundos de novas tecnologias. A articulação da produção de saberes entre as universidades, institutos de pesquisas, setor regulado, organizações da sociedade, é o desafio para uma atuação mais presente e consciente dessa política de proteção.

Dallari \& Nunes Júnior 39 afirmam que para tornar efetivo o sistema de vigilância sanitária, não basta a existência de leis adequadas ao anseio de eliminar, diminuir ou prevenir riscos à saúde. É preciso também que existam operadores do sistema jurídico que "falem a língua do direito sanitário”. É necessário, enfim, conduzir uma ação política, determinando, em cada situação, qual é o melhor estado da arte envolvido e, analisando as repercussões socioeconômicas e culturais do problema, estabelecer um adequado e eficaz sistema de vigilância e de alerta, contando com a participação ativa das pessoas para que se possa estabelecer a correta relação custo/benefício, indispensável à tomada de decisão política.

Ao trazer um olhar renovado sobre a questão do flúor em alimentos, acredita-se que, a 
partir das discussões apresentadas, a vigilância sanitária possa abordar o tema como sendo uma demanda que necessita de ações inovadoras e democráticas para que se produzam resultados efetivamente positivos na saúde da população.

\section{Considerações finais}

Neste estudo foi possível verificar que a abordagem da vigilância sanitária sobre as concentrações de flúor em produtos alimentícios é extremamente necessária, mas ainda, incipiente.
Há um descompasso entre produção científica e ações da vigilância sanitária. A regulamentação sobre o tema é necessária, mas não suficiente, por si só, para abordar todos os aspectos sobre ingestão de flúor. Os processos de comunicação do risco sanitário, educação em saúde e orientação da população precisam ser implementados, bem como o da capacitação dos trabalhadores da vigilância sanitária e profissionais de saúde. Ademais, questões do flúor nos rótulos precisam de um maior aprofundamento, especialmente sobre os aspectos de compreensão dos consumidores para a efetividade da medida.

\section{Resumo}

O estudo analisou os posicionamentos do poder público federal (Brasil), estadual (São Paulo), municipal (Bauru, São Paulo), de representantes da sociedade, do setor regulado e de associações brasileiras ligadas à pesquisa científica, sobre as questões do flúor em alimentos. A análise dos depoimentos $(N=15)$ foi realizada através de metodologia qualitativa (teoria do Discurso do Sujeito Coletivo). Várias ideias centrais foram verificadas, tais como: necessidade de maior atuação da vigilância sanitária no monitoramento e controle das concentrações de flúor; ações educativas e necessidade de mais pesquisas na área. Concluiuse que a abordagem da vigilância sanitária sobre as concentrações de flúor em alimentos é necessária, mas ainda incipiente. Há descompasso entre a produção científica e as ações da vigilância. A regulamentação não é suficiente, por si só, para resolver todas as questões do tema abordado. A comunicação do risco sanitário e as ações de educação em saúde precisam ser implementadas. As questões do flúor nos rótulos carecem de um maior amadurecimento para que a medida seja efetiva.

Fluorose Dentária; Flúor; Alimentos; Pesquisa Qualitativa; Vigilância Sanitária

\section{Colaboradores}

P. A. P. Bardal participou das fases de concepção do projeto, coleta, análise e interpretação dos dados, redação e revisão do artigo. K. P. K. Olympio e M. A. R. Buzalaf colaboraram nas fases de concepção do projeto e revisão do artigo. S. G. Dallari contribuiu na concepção do projeto, revisão do artigo e orientação da pesquisa.

\section{Agradecimentos}

À Coordenação de Aperfeiçoamento de Pessoal de Nível Superior (CAPES), pela bolsa de estudos concedida durante os quatro anos do curso de doutorado. 


\section{Referências}

1. Mascarenhas AK. Risk factors for dental fluorosis: a review of the recent literature. Pediatr Dent 2000; 22:269-77.

2. Buzalaf MA, Granjeiro JM, Duarte JL, Taga ML. Fluoride content of infant foods in Brazil and risk of dental fluorosis. ASDC J Dent Children 2002; 69:196-200.

3. Buzalaf MAR, Granjeiro JM, Cardoso VES, Silva TL, Olympio KPK. Fluorine content of several brands of chocolate bars and chocolate cookies found in Brazil. Pesqui Odontol Bras 2003; 17:223-7.

4. Narvai PC. Cárie dentária e flúor: uma relação do século XX. Ciênc Saúde Coletiva 2000; 5:381-92.

5. Luchessi G. Globalização e regulação sanitária: rumos da vigilância sanitária no Brasil [Tese de Doutorado]. Rio de Janeiro: Escola Nacional de Saúde Pública, Fundação Oswaldo Cruz; 2001.

6. Lefèvre F, Marques MCC, Lefèvre AMC, Latorre MRD, Balbinot R, Medeiros IY, et al. Representação social da vigilância sanitária pela população do município de Águas de Lindóia: análise da percepção de alguns riscos relevantes. Revista Brasileira de Vigilância Sanitária 2005; 1:22-30.

7. Cruz V. Transparência e accountability na regulação da vigilância sanitária no Brasil. Rev Direito Sanit 2009/2010; 10:90-114.

8. Aith F, Dallari SG. Vigilância em saúde no Brasil: os desafios dos riscos sanitários do século XXI e a necessidade de criação de um sistema nacional de vigilância em saúde. Rev Direito Sanit 2009; 10: 94-125.

9. Jodelet D. Répresentations sociales: un domaine en expansion. In: Jodelet D, editor. Répresentations sociales. Paris: PUF; 1989. p. 31-61.

10. Lefèvre F, Lefèvre AMC. O discurso do sujeito coletivo: um novo enfoque em pesquisa qualitativa (desdobramentos). Caxias do Sul: EDUCS; 2003.

11. Lefèvre F, Lefèvre AMC, Marques MCC. Discurso do sujeito coletivo, complexidade e auto-organização. Ciênc Saúde Coletiva 2009; 14:1193-204.

12. Lefèvre F, Lefèvre AMC, Cornetta VK, Araújo SDT. O discurso do sujeito coletivo como eu ampliado: aplicando a proposta em pesquisa sobre a pílula do dia seguinte. Rev Bras Crescimento Desenvolv Hum 2010; 20:798-808.

13. Hartz ZMA, Vieira-da-Silva LM, organizadores. Avaliação em saúde: dos modelos teóricos à prática na avaliação de programas e sistemas de saúde. Salvador: EdUFBA/Rio de Janeiro: Editora Fiocruz; 2005.

14. Moysés SJ. Intersetorialidade e multidisciplinaridade como desafios para a odontologia. In: Pereira AC, organizador. Tratado de saúde coletiva em odontologia. Nova Odessa: Napoleão; 2009. p. 59-71.

15. Cangussu MCT, Castellanos Fernandez RA, Rivas CC, Ferreira Jr. C, Santos LCS. Prevalência da fluorose dentária em escolares de 12 e 15 anos de idade em Salvador, Bahia, Brasil, 2001. Cad Saúde Pública 2004; 20:129-35.

16. Moysés SJ, Moysés, ST, Allegretti, ACV, Argenta, M, Werneck R. Fluorose dental: ficção epidemiológica? Rev Panam Salud Pública 2002; 12:339-56.
17. Pereira AC, organizador. Tratado de saúde coletiva em odontologia. Nova Odessa: Napoleão; 2009.

18. Sampaio FC. Flúor: pesquisas atuais. In: Dias AA, organizador. Saúde bucal coletiva: metodologia de trabalho e práticas. São Paulo: Editora Santos; 2006. p. 174-86.

19. Moysés ST, Moysés SJ. Fluorose dentária. In: Antunes JLF, Peres MA, organizadores. Epidemiologia da saúde bucal. Rio de Janeiro: Editora Guanabara Koogan; 2006. p. 115-27.

20. Dallari SG. Organização jurídica da administração pública em saúde. In: Rozenfeld S, organizadora. Fundamentos da vigilância sanitária. Rio de Janeiro: Editora Fiocruz; 2000. p. 113-33.

21. Tancredti RCP, Barreto AF, Tancredti JGR. Direito e saúde: a discricionariedade nas ações fiscais da vigilância sanitária de alimentos. Rev Direito Sanit 2007; 8:31-42.

22. Ely HC, Cesa KT, Aerts DRGC. Vigilância da saúde bucal. In: Antunes JLF, Peres MA, organizadores. Epidemiologia da saúde bucal. Rio de Janeiro: Editora Guanabara Koogan; 2006. p. 295-321.

23. Dallari SG. A participação popular e o direito à saúde no sistema nacional de saúde brasileiro. Rev Direito Sanit 2005; 6:9-24.

24. Barreto ML. O conhecimento científico e tecnológico como evidencia para políticas e atividades regulatórias em saúde. In: Costa EC, organizador. Vigilância sanitária: desvendando o enigma. Salvador: EdUFBA; 2008. p. 91-106.

25. Coordenação Geral de Desenvolvimento Científico Tecnológico, Ministério da Saúde. Anais da I Conferência Nacional de Ciência e Tecnologia em Saúde. Brasília: Ministério da Saúde; 1994.

26. Coimbra Jr. CEA. Desafios da produção e da comunicação científica em saúde no Brasil. Cad Saúde Pública 2003; 19:4-5.

27. Funtowicz SO, Ravetz JR. Science for the post-normal age. Futures 1993; 25:739-55.

28. Sampaio FC. Toxicidade crônica dos fluoretos. In: Buzalaf MAR, organizador. Fluoretos e saúde bucal. São Paulo: Editora Santos; 2008. p. 87-100.

29. Teixeira ACC, Estima CCP, Toassa EC, Leal GVS, Lefèvre F, Philippi ST. Rótulos dos alimentos: como as pessoas entendem a informação nutricional? Nutrição em Pauta 2010; 10:49-53.

30. Cervato-Mancuso AM, Gambardella AMD, Bastos DHM, Marchion DML, Torres EAFS, Marucci MFN, et al. Nutrição e alimentação em saúde publica. In: Rocha AA, César CLG, organizadores. Saúde pública: bases conceituais. São Paulo: Editora Atheneu; 2008. p. 179-96.

31. Câmara MCC, Marinho CLC, Guilam MC, Braga AMCB. A produção acadêmica sobre a rotulagem de alimentos no Brasil. Rev Panam Salud Pública 2008; 23: 52-8.

32. Coutinho JG. Estabelecimento de alegação de saúde nos rótulos de alimentos e bebidas embalados [Dissertação de Mestrado]. Brasília: Universidade de Brasília; 2004. 
33. Martins BR. Análise do hábito de leitura e entendimento/recepção das informações contidas em rótulos de produtos alimentícios embalados, pela população adulta freqüentadora de supermercados, no Município de Niterói/RJ [Dissertação de Mestrado]. Rio de Janeiro: Fundação Oswaldo Cruz; 2004.

34. Silva MZT. Influência da rotulagem nutricional sobre o consumidor [Dissertação de Mestrado]. Recife: Universidade Federal de Pernambuco; 2003.

35. Pereira Lima C, Focesi MCP, Campos NZR, L'abbate S. Health promotion, health education and social communication on health: specificities, interfaces, intersections. Promot Educ 2000; 4:8-12.

36. Rocha AA, César CLG, organizadores. Saúde pública: bases conceituais. São Paulo: Editora Atheneu; 2008.
37. Costa EA, Rozenfeld S. Constituição da vigilância sanitária no Brasil. In: Rozenfeld S, organizadora. Fundamentos da vigilância sanitária. Rio de Janeiro: Editora Fiocruz; 2000. p. 15-40.

38. Vecina Neto G, Marques MC, Figueiredo AM. Vigilância sanitária no Brasil. In: Campos GWS, Minayo MCS, Akerman M, Drumond Júnior M, Carvalho YM, organizadores. Tratado de saúde coletiva. São Paulo: Editora Hucitec/Rio de Janeiro: Editora Fiocruz; 2006. p. 689-713.

39. Dallari SG, Nunes Júnior VS. Direito sanitário. São Paulo: Editora Verbatim; 2010.

Recebido em 15/Mar/2011

Versão final reapresentada em 05/Out/2011 Aprovado em 21/Nov/2011 